\title{
EchoGéo
}

$13 \mid 2010$

Afrique, 50 ans d'indépendance : État et territoires

\section{Références bibliographiques de congrès concernant les indépendances des pays africains, publiés entre 1960 et 2010.}

Bernadette Joseph

\section{CpenEdition}

Journals

Édition électronique

URL : https://journals.openedition.org/echogeo/12097

DOI : 10.4000/echogeo.12097

ISSN : 1963-1197

Éditeur

Pôle de recherche pour l'organisation et la diffusion de l'information géographique (CNRS UMR 8586)

Référence électronique

Bernadette Joseph, «Références bibliographiques de congrès concernant les indépendances des pays africains, publiés entre 1960 et 2010. », EchoGéo [En ligne], 13 | 2010, mis en ligne le 20 septembre 2010, consulté le 03 août 2021. URL : http://journals.openedition.org/echogeo/12097 ; DOI : https://doi.org/10.4000/echogeo.12097

Ce document a été généré automatiquement le 3 août 2021.

EchoGéo est mis à disposition selon les termes de la licence Creative Commons Attribution - Pas d'Utilisation Commerciale - Pas de Modification 4.0 International (CC BY-NC-ND) 


\title{
Références bibliographiques de congrès concernant les indépendances des pays africains, publiés entre 1960 et 2010.
}

\author{
Bernadette Joseph
}

\section{NOTE DE L'ÉDITEUR}

La liste qui suit est présentée selon la date à laquelle s'est tenu le congrès.

\section{3}

2 Décolonisation et régimes politiques en Afrique noire.

Actes du colloque organisé par le Centre d'études des relations internationales de Paris et le Centre d'études d'Afrique noire de l'université de Bordeaux, 30 novembre- $1^{\text {er }}$ décembre 1963, sur le thème "Les régimes des nouveaux Etats et leurs relations extérieures. Sous la direction d'Albert Mabileau et Jean Meyriat.- Paris : Colin, 1967.$276 \mathrm{p}$.

$3 \quad 1977$

4 The transfer of power in Africa: decolonization, 1940-1960.

D'après le congrès tenu à Bellgadio, septembre-octobre 1977. Ed. by Prosser Cilfford and William Roger Louis.- New Haven : Yale University press, 1982.- 654 p.

1978

6 La décolonisation de l'Afrique: Afrique australe et corne de l'Afrique.

Documents de travail et compte rendu de la réunion d'experts tenue à Varsovie, Pologne, 9-13 octobre 1978.- Paris: presses de l'UNESCO, 1981.- 180 p. (version anglaise).

$7 \mathbf{1 9 7 9}$ 
Actes du colloque organisé par le Centre Bordelais d'études africaines, le Centre d études d'Afrique noire et l'Institut Charles de Gaulle, Bordeaux, 19-20 octobre 1979.Paris : Pédone, 1981.- XIV-421 p.

\section{5-1985.}

Actes du colloque de Bruxelles, 7-9 juin 1985.- Bruxelles : Centre Guillaume Jacquemyns, 1986.- $308 \mathrm{p}$.

Décolonisation de l'Afrique vue par les africains.

Actes du colloque organisé par le Centre culturel africain, Paris, 14 décembre1985.Paris : L'harmattan, 1987.- $171 \mathrm{p}$.

and society in francophone Africa since independence.

Actes d'un congrès tenu à Oxford en avril 1988.- Basingstoke : Mac Millan Press ; New York : St Martin Press, 1995.- XX-280 p.

La Tunisie de l'après guerre.

Actes du V colloque international sur la Tunisie d'après guerre 1945-1950 organisé par l'Institut supérieur d'histoire du mouvement national ( ISHMN) de la faculté des sciences humaines de l' Université de Tunis, Tunis, 26-28 mai 1989.- Tunis : université de Tunis, 1991.- 415 p. (voir aussi la collection « Publications de l'ISHMN »).

\section{propagande coloniale et à la représentation des africains et de l'Afrique en France, de 1920 aux} indépendances.

Actes du colloque organisé par l'Association Connaissance de l'Histoire de l'Afrique contemporaine (ACHAC), Paris, 20-22 janvier 1992.- Paris : Syros/ACHAC, 1993.- 157 p. (numéro spécial « Plein Sud »).

22 Mémoire et enseignement de la guerre d'Algérie.

Actes du colloque organisé par l'Institut du Monde Arabe et la Ligue de l'enseignement, Paris, 13-14 mars 1992. Rédaction et mise au point des actes par Abedel Jalil Laamiri, Jean-Michel le Dain et Gilles Manceron.- Paris : Institut du Monde Arabe, Ligue de l'enseignement, 1993.- 2 vol, 607 p.

23 Les accords d'Evian en conjoncture et en longue durée.

Actes du colloque organisé par l' Institut Maghreb-Europe et le Centre d'histoire 
économique et sociale Jean Bouvier, université Paris 8 Saint Denis, 19-21 mars 1992Paris : Karthala ; Saint Denis: Institut Maghreb-Europe, 1997.- 265 p. (collection Hommes et sociétés). 1994

La conférence de Brazzaville de 1944, contexte et repères : cinquantenaire de la décolonisation. Raymond Marin Lemesle.- Paris : CHEAM, diff. Documentation française, 1994.- 132 p.

Le retour des rois : les autorités traditionnelles et l'Etat en Afrique contemporaine.

Contributions au colloque international « Rois et chefs dans les états africains de la veille des indépendances à la fin $\mathrm{du} \mathrm{XX}^{\mathrm{e}}$ siècle " organisé par le Centre d'études africaines de l'Université Paris1, Paris, 8-10 novembre1994. Sous la direction de ClaudeHélène Perrot et François-Xavier Fauvelle-Aymar.- Paris: Karthala, 2003.- 568 p. (collection Hommes et sociétés).

Les relations franco-tunisiennes au miroir des élites XIX-XX siècles.

Actes du colloque international organisé par le département d'histoire de la faculté des lettres Manouba, Tunis, 2-3 décembre 1994. Textes réunis par Noureddine Douguis.Tunis: Faculté des lettres Manouba, 1997.-277p. (collection Publications de la faculté des lettres , série colloques ; 13).

\section{5}

Medi Ben Barka : de l'indépendance marocaine à la Tricontinentale.

Actes du colloque organisé par l'Institut Maghreb-Europe et la revue Politis, université Paris 8 St Denis, 17-18 novembre 1995.- Paris: Karthala, 1997.- 214 p. (collection Hommes et sociétés).

1996

Marseille et le choc des décolonisations : les rapatriements 1954-1964.

Actes du colloque organisé par l' UMR TELEME, la MMSH et l'Association des archives de la ville de Marseille. Sous la direction de Jean-Jacques Jordi et Emile Temine.- Aix-enProvence : Edisud, 1996.- 222 p.

Méditerranée, le pacte à construire.

Actes $\mathrm{du}$ colloque organisé par la fondation méditerranéenne d'études stratégiques(FMES), l'Universidad Complutense de Madrid (UNISCI), le Centre de recherches et d'études sur les stratégies et les technologies (CREST), Marseille, 20-22 juin 1996.- Paris : Publisud, 1997.- 276 p. (collection Strademed ; 3).

\section{7}

Madagascar : refondation et développement, quels enjeux pour les années 2000 ?

Actes du colloque organisé par la Société des Amis de Madagascar, 27 novembre 1997. Sous la direction de Patrick Rajoelina.- Paris: Harmattan, 1998.- 151 p.

\section{0}

Un colonialismo, due sponde del Mediterraneo.

Atti del seminario di studi Italo-Libici, Siena-Pistoia, 13-14 gennaio 2000.- Pistoia : CRT, 2000.- 169 p. (Collana studie e richerche, 4).

Colonisation, décolonisation, postcolonialisme.

Conférence organisée pour la "Mission 2000 en France ", 3 novembre 2000. Elikia M' Bokolo.- Paris : Université de tous les savoirs; Vanves: CERIMES, 2005 .- 1 DVD 1h30. 
Coloquio internacional Encontro Portugal /Africa, Brown University (USA), 2002.Lisboa : Imprensa de ciencias sociales, 2004.- 393 p.

Pour une nouvelle donne, France et Afrique.

Actes du colloque «Vers de nouvelles relations entre la France et l'Afrique » organisé par la Fondation Gabriel Péri et le Parti de l'indépendance et du travail du Sénégal, Dakar, 1-2 décembre 2005.- Paris: Fondation Gabriel Péri, 2006.- 223p. (collection Actes).

La Réunion et l'océan indien, la décolonisation au XXI' siècle.

Actes du colloque de Saint Denis de la Réunion organisé/ par le Centre de recherches et d'études des sociétés de l'océan indien (CRESOI) de l'Université de la Réunion, 23-25 octobre 2006. Sous la direction de Yvan Combeau.- Paris: les Indes savantes, 2007.$260 \mathrm{p}$.

2007

National days : constructing and mobilising national identity.

Contributions présentées lors d'une conférence à l'université de Glasgow, 2007. Ed. by David Mc Crone, Gayle mc Pherson.- Basingstoke ; New York : Macmillan, 2009.XIV-232p.

46 La Quatrième République et l'Outre-Mer français.

Actes du colloque organisé par le Centre d'histoire de sciences politique, avec le concours du CRESOI, Paris, 29-30 novembre 2007. Sous la direction de Pascal Gauchy, Yvan Combeau, Jean-François Sirinelli- Paris : Société française d'histoire d'Outre- Mer, 2009.- 154 p. 